울주 천전리 각석의 장기 모니터링을 통한 식생지수 변화 분석

\title{
Analysis of Changes in Vegetation Index Through Long-term Monitoring of Petroglyphs of Cheonjeon-ri, Ulju
}

\author{
안유빈 ${ }^{1}$, 유지현 ${ }^{1}$, 전유근 ${ }^{2}$, 이명성 ${ }^{1}{ }^{*}$ \\ ${ }^{1}$ 국립문화재연구소 보존과학연구실, ${ }^{2}$ 한국문화재재단 국제교류팀 \\ Yu Bin Ahn', Ji Hyun Yoo', Yu Gun Chun², Myeong Seong Lee ${ }^{1,{ }^{*}}$ \\ ${ }^{1}$ Conservation Science Division, National Research Institute of Cultural Heritage, Daejeon 34122, Korea \\ ${ }^{2}$ International Cooperation Team, Korea Cultural Heritage Foundation, Seoul 06153, Korea
}

\author{
Received September 27, 2021 \\ Revised October 19, 2021 \\ Accepted November 2, 2021 \\ *Corresponding author \\ E-mail: mslee75@korea.kr \\ Phone: +82-42-860-9081 \\ Journal of Conservation Science \\ 2021;37(6):659-669 \\ https://doi.org/10.12654/JCS.2021. \\ 37.6.05 \\ pISSN: 1225-5459, eISSN: 2287-9781 \\ (C) The Korean Society of \\ Conservation Science for Cultural \\ Heritage \\ This is an Open-Access article distributed \\ under the terms of the Creative \\ Commons Attribution Non-Commercial \\ License (http://creativecommons.org/ \\ licenses/by-nc/3.0) which permits \\ unrestricted non-commercial use, \\ distribution, and reproduction in any \\ medium, provided the original work is \\ properly cited.
}

\begin{abstract}
초 록 이 연구에서는 초분광 영상을 기반으로 산출된 식생지수를 활용하여 2014년부터 2020 년까지 울주 천전리 각석에 대한 모니터링을 수행하였다. 모니터링에 적합한 식생지수 선정을 위해 실내분석을 수행하였고, 생물오염에 대한 민감도를 고려하여 NDVI와 TVI를 선정하였다. 선정된 식생지수를 활용하여 모니터링을 수행한 결과, NDVI는 2014년부터 2018년까지 증가하 는 경향을 보이고 보존처리 이후인 2020년 감소하였으나, TVI는 모니터링 시점에 따른 경향성 을 확인하기 어려웠다. 이러한 경향은 연도별 촬영조건에 따른 분광반사율 편차에서 기인하는 것을 확인하였다. 이때 $\mathrm{NDVI}$ 는 TVI보다 분광반사율 편차에 대한 민감도가 낮아 모니터링에 활용할 수 있을 것으로 판단되며, TVI의 활용을 위해서는 심화연구가 필요하다.
\end{abstract}

중심어 석조문화재, 식생지수, 초분광 영상, 모니터링, VNIR

ABSTRACT In this study, vegetation index, the vegetation index calculated based on hyperspectral images was used to monitor Petroglyphs of Cheonjeon-ri, Ulju from 2014 to 2020 . To select suitable the vegetation index for monitoring, indoor analysis was performed, and considering the sensitivity to biocontamination, Normalized Difference Vegetation Index (NDVI) and Triangular Vegetation Index (TVI) were selected. As a result of monitoring using the selected vegetation index, NDVI increased from 2014 to 2018 and then decreased in 2020, after preservation treatment. On the other hand, TVI was difficult to confirm the tendency during the monitoring. This difference was due to the variation in spectral reflectance according to the photographing conditions by year. Therefore NDVI is less sensitive to spectral reflectance deviation than TVI, so it can be used for monitoring. In order for TVI to be used, however, in-depth study is needed.

Key Words Stone cultural heritage, Vegetation index, Hyperspectral image, Monitoring, VNIR

\section{1. 서 론}

문화재청에서는 국가지정문화재 가운데 국민적 관심 도와 상징성이 크고 인위적, 자연적 요인 등으로 훼손도, 노후도 등이 높아 특별 관리가 필요한 문화재 56 건을 선 정하고 중점 관리대상 문화재로 명명하였다. 이 문화재들 은 훼손을 사전에 예방하고 보존관리 체계 강화를 위해 각 문화재의 보존현황에 따른 구조 변형 여부와 재료 열 화상태, 생물피해 등에 대한 주기적 정밀점검이 수행되었 다(Cultural Heritage Administration, 2016).
이와 같은 중점 관리대상 문화재로 선정된 국보 울주 천전리 각석은 울산광역시 울주군 두동면 천전리 산 210-2번지에 소재하고 있으며, 표면에는 복합적인 오염이 발생한 상태였다. 2009년 조사에 따르면 균열, 탈락, 박리, 박락, 변색, 생물오염 등 다양한 훼손 유형에 의해 표면이 손상되어 있었고(National Research Institute of Cultural Heritage, 2009), 2014년 조사에서도 동일한 양상의 손상요 인들이 관찰되었다.

언급된 손상요인 중 VNIR(400-1000 nm) 대역의 초분 광 카메라를 활용하여 진단할 수 있는 것은 변색과 생물 
오염과 변색이다. 이 중 생물로 인한 오염은 지속적으로 성장하기 때문에 모니터링이 중요하다. 국외에서는 석조 문화재 표면의 생물오염 분석을 위해 형광 라이다와 같은 분광장비를 활용하여 생물을 모니터링하거나, 디지털 이 미지 분석을 통해 변색을 진단하는 연구가 수행된 사례가 있다(Cecchi et al., 2000; Pantani et al., 2000; Vázquez et al., 2011). 국내에서도 반사 분광학적 특성을 통한 진단과 지상용 초분광 카메라를 활용한 이미지 분석법을 석조문 화재 진단에 적용한 사례가 있다(Hyun and Park, 2010; Chun et al., 2015; Ahn et al., 2020). 그러나 초분광 영상을 활용하여 석조문화재에 발생한 생물에 대한 중장기적 모 니터링을 수행된 사례는 부족한 실정이다.

기하학적인 문양과 각자 등이 새겨진 울주 천전리 각 석의 가치를 고려할 때 표면에 생장하는 생물은 손상을 가속시킬 가능성이 있으므로 정밀한 모니터링이 요구된 다. 따라서 사전조사를 통해 확인된 표면상태를 고려하여 초분광 카메라를 활용한 모니터링이 계획되었고, 2014년 부터 2020년까지 초분광 영상을 기반으로 모니터링 자료 를 구축하였다. 그러나 연도별 촬영 조건이 상이하기 때 문에 측정 환경에 민감하지 않은 모니터링 방법이 요구되 었다.

따라서 이 연구에서는 초분광 영상을 활용한 모니터링 의 기술적 기반에 기여하고자, 식생지수를 활용하여 울주 천전리 각석의 장기 모니터링 자료를 비교하였다. 우선 장기 모니터링에 적합한 식생지수를 선정하기 위해 실내 에서 취득한 초분광 영상을 활용하여 다양한 식생지수에 대한 사전 검토를 수행하였다. 이후 선정된 식생지수를 실제 현장자료에 적용하여 연도별 변화를 비교하였다. 또 한 보존처리를 통해 표면오염물이 제거된 후 초분광 영상 을 취득하여 이전 시점의 모니터링 자료와 비교하였고, 연구 결과를 바탕으로 식생지수의 적용 가능성에 대하여 검토하였다.

\section{2. 이론적 배경}

석조문화재에 발생하는 생물열화는 생물학적 유기체 가 역사적, 예술적 또는 경제적으로 중요한 대상에 미치 는 물리적 및 화학적 손상이며, 일반적으로 석조문화재에 서 발생하는 생물오염은 조류, 지의류, 선태류와 같은 하 등생물이다. 이와 같은 하등생물들은 생물의 천이 과정에 의해 발생하며, 암석의 기계적인 풍화를 가속하는 것으로 알려져 있다(Griffin et al., 1991; Lee et al., 2001; Min, 2018). 또한 우리나라의 석조문화재에는 다양한 생물이 서식하고 있는데, 이끼류와 지의류가 대표적이며 미세조
류와 시아노세균, 곰팡이, 세균도 서식하는 것이 확인된 다. 이 중 지의류는 균류와 조류의 공생체로 습기가 없고 건조한 석조문화재 표면에도 무성생식이나 유성생식에 의한 방법으로 착생하여 생장할 수 있고, 지의산을 만들 어내 암석의 표면을 부식시킨다(Min, 1985; Han and An, 1990).

석조문화재의 생물오염에 대한 모니터링은 손상지도 작성, 그리드 설정법을 통한 모니터링, 이미지 분석을 이 용한 훼손 양상별 분류를 수행하는 방법 등이 사용되어 왔다(Jo and Lee, 2011; Park et al., 2013; Chun et al., 2014; Lee et al., 2019). 또한 생물풍화를 알아보기 위한 정량적 인 방법으로 엽록소-a의 양을 측정하는 방법, 색을 기준으 로 나누는 방법, 생물종을 동정하는 연구가 수행되었다 (Oh, 2008; Kim et al., 2010; Kim et al., 2011; Kim et al., 2017; Park et al., 2020). 이와 같은 방법들이 갖는 한계점 은 지속적인 발전을 통해 개선되었음에도 불구하고, 생물 오염과 무기물 간의 경계를 구분할 수 있는 분석법이 필 요한 실정이다.

초분광 이미징은 공간정보에 분광 기술을 더한 것으로 전자기파의 스펙트럼 밴드에 따른 2 차원적 영상정보를 초분광 큐브 형태로 구성하여 대상체의 상태, 구성, 특징, 변이 등을 도출하는 기술을 의미한다(Lee et al., 2019). 초 분광 영상은 분광밴드가 많고, 연속적이고, 파장폭이 좁 다는 세 가지 특징을 가지며(Kim et al., 2005), 이와 같은 특징을 활용함으로써 생물오염과 무기물이 병존하는 석 조문화재 표면에 대한 분류가 가능하다.

특히 빛이 식생에 닿으면 스펙트럼의 일부가 반사되는 데 식물의 반사도는 잎 표면의 특성, 내부구조, 생화학적 성분의 농도 및 분포에 좌우되며 반사광의 분석을 통해 식물의 단위 면적당 식물량과 생리적 상태를 모두 평가할 수 있다(Penuelas and Filella, 1998).

석조문화재 표면에 서식하는 식생은 천이 과정을 통해 생물막을 생성하는데, 이때 생물체가 생존하기 위해 빛에 너지를 화학에너지로 전환하는 광합성 과정이 수행된다. 광합성은 특별한 광합성 색소가 있어야 하며, 광합성 색 소는 엽록소(chlorophyll), 카로티노이드(carotinoid), 크산 토필(xanthophyll), 피코에리트린(phycoerythrin), 피코시아 닌(phycocyanin) 등이 있다(Min, 2018).

이러한 광합성 색소들은 흡수하는 파장이 상이하다. 엽록소에는 여러 종류의 색소가 있어 각기 다른 파장의 빛을 흡수하는데, 엽록소-a는 주로 청색, 보라색, 적색의 빛을 흡수하고 녹색 빛을 반사시키므로 녹색으로 보인다. 엽록소-b는 주로 청색과 주황색 빛을 흡수하고 황록색을 반사하여 황록색으로 보인다(Min, 2018). 이외 보조색소 
인 카로티노이드는 400-500 nm 대역의 흡수대를 가지고 주 황색을 띠며, 피코시아닌과 피코에리트린은 각각 $630 \mathrm{~nm}$ 와 $550 \mathrm{~nm}$ 에서 흡수대를 가진다(Lee et al., 2016).

1960 년대 이래 원격탐사 자료로부터 식물의 생물리학 적 특성을 나타내는 다양한 인자들을 밝혀내고자 하는 연 구가 수행되어 다양한 식생지수가 개발되었다. 식생지수 는 녹색식물의 상대적 분포량과 활동성, 엽면적지수, 엽 록소 함량, 엽량 및 광합성 흡수 복사량 등과 관련된 지표 로 사용된다(Shin and Kim, 2003). 바이오매스 또는 잎면 적 지수를 추정하기 위한 근적외선/적외선 비율 방법은 Jordan(1969)에 의해 처음 보고되었으며, Rouse et al.(1974) 는 정규식생지수(NDVI)를 개발하여 사용하였고, 이는 다 중분광 영상에서 일반적으로 사용하는 식생지수가 되었 다. 그 밖에 현재까지 제안되고 있는 식생지수는 약 50 여 종 이상이 있다(Na et al., 2018). 이러한 식생지수는 문화 재 진단을 위해 활용된 사례가 있지만(Kim et al., 2016; Lee et al., 2020), 중장기적으로 적용한 사례가 부족하다.

이와 같은 식생지수는 산림이나 작물 모니터링 등 광 역 조사에 일반적으로 활용되며, 지상용 초분광 장비보다 위성 혹은 항공 촬영 영상에 활용된다. 따라서 석조문화 재 표면의 조류와 지의류 등 하등생물로 인한 오염 모니 터링에 식생지수를 활용하기 위해서는 지상용 초분광 장 비에 식생지수를 적용하여 검토하는 과정이 선행되어야 하며, 다양한 식생지수의 특성을 고려한 적용성 평가가 필요하다.

\section{3. 연구자료 및 방법}

\section{1. 초분광 시스템 및 자료}

울주 천전리 각석 모니터링 자료는 VNIR $(400-1000 \mathrm{~nm})$ 대역의 초분광 영상이다. 이 영상은 하나의 이미지로 구 현되나 픽셀마다 고유의 분광 특성을 가지고 있다. 특히 VNIR 대역은 앞서 언급한 식생의 생물리적 특성으로 인 해 나타나는 분광학적 특징 구분이 용이하다.

초분광 영상을 취득하기 위한 센서는 회전(rotating) 방 식의 가시광-근적외선 영역대(400-1000 nm) 초분광 카메 라(VNIR Spectral Camera PS V10E, Specim, FIN)와 카메라 를 제어하는 컴퓨터로 구성된다. 카메라는 수평으로 $180^{\circ}$ 회전이 가능하며, 가용 파장대역에서 258 개의 밴드를 획 득한다(Figure 1A, 1B).

울주 천전리 각석의 자료는 2014 2020년까지 2년 주 기로 촬영되었다(Figure 1C). 2014년, 2016년, 2018년까지 3 건의 자료는 표면 오염물 모니터링을 위해 취득하였고, 2020년 자료는 2019년 보존처리가 수행된 이후 자료로서 비교군으로 활용하기 위해 촬영하였다. 각각의 영상은 동 일한 대상을 촬영하였으나, 측정일과 기하조건이 상이하 다(Figure 1C).

또한 식생지수 선정을 위해 야지에서 복합적인 손상이 관찰되는 암석을 수습하였고, 동일한 초분광 카메라로 촬 영하여 현장적용을 위한 선행연구에 활용하였다. 촬영은 실내에서 수행되었고 광원은 할로겐 램프(H1000, Fomax,

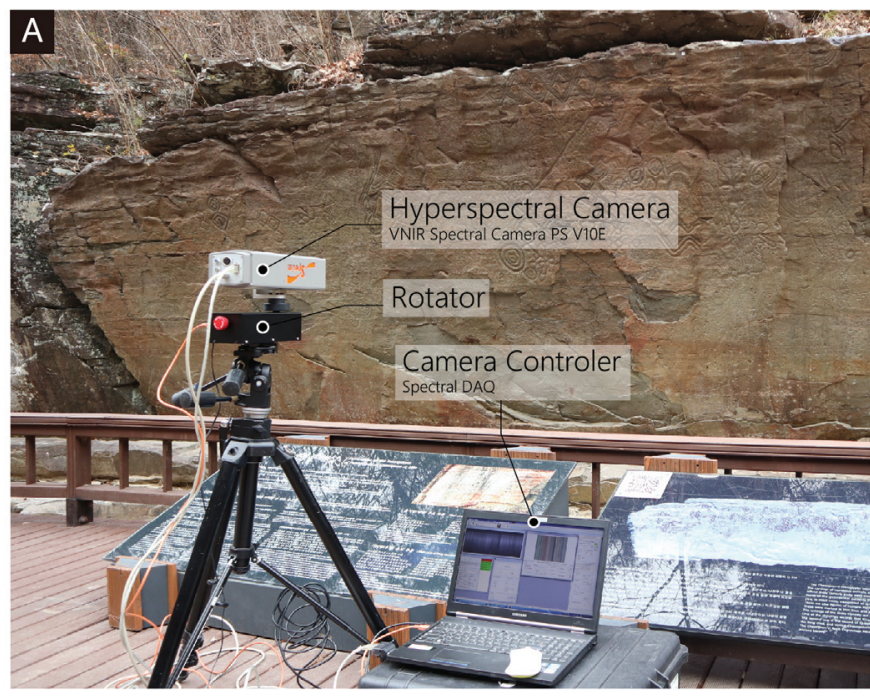

\begin{tabular}{|c|c|c|c|}
\hline \multicolumn{4}{|c|}{ Hyperspectral Camera Optical Characteristics } \\
\hline & $\mathrm{nge}(\mathrm{nm})$ & \multicolumn{2}{|c|}{$400-1000$} \\
\hline Resol & spatial×spectral) & \multicolumn{2}{|c|}{$1392 \times 1040$ (950 active) } \\
\hline & trograph & \multicolumn{2}{|c|}{ V10E } \\
\hline & Resolution & \multicolumn{2}{|c|}{$2.8 \mathrm{~nm}(30 \mu \mathrm{m}$ slit $)$} \\
\hline & al Sampling & \multicolumn{2}{|c|}{$0.63-5.06 \mathrm{~nm} / \mathrm{pixel}$} \\
\hline & Resolution & \multicolumn{2}{|c|}{ RMS spot diameter $<18 \mu \mathrm{m}$} \\
\hline & cal Aperture & \multicolumn{2}{|c|}{$F / 2.4$} \\
\hline \multirow{2}{*}{\multicolumn{2}{|c|}{ Acquisition Date }} & \multicolumn{2}{|c|}{ Solar geometry } \\
\hline & & altitude & azimuth \\
\hline $1 s t$ & October 24, 2014 & $40^{\circ} 51^{\prime} 11^{\prime \prime}$ & $161^{\circ} 33^{\prime} 23^{\prime \prime}$ \\
\hline 2nd & September 01, 2016 & $36^{\circ} 20^{\prime} 19^{\prime \prime}$ & $108^{\circ} 00^{\prime} 36^{\prime \prime}$ \\
\hline $3 r d$ & November 13, 2018 & $09^{\circ} 55^{\prime} 13^{\prime \prime}$ & $120^{\circ} 34^{\prime} 01^{\prime \prime}$ \\
\hline 4th & November 26,2020 & $14^{\circ} 56^{\prime} 19^{\prime \prime}$ & $130^{\circ} 18^{\prime} 34^{\prime \prime}$ \\
\hline
\end{tabular}

Figure 1. Status of hyperspectral imaging system in Petroglyphs of Cheonjeon-ri, Ulju. (A) Hyperspectral imaging system. (B) Characteristics of hyperspectral camera sensors. (C) The monitoring date and the location of the sun on the image acquisition date. 
KOR)를 이용하였다. 이때 주변에서 유입되는 반사광의 영향을 최소화하기 위해 최대한 외부광을 차단한 환경에 서 촬영을 수행하였다.

\section{2. 영상 보정}

초분광 시스템으로 취득되는 영상은 각각의 픽셀에 대 응하는 고유한 분광 정보를 가지고 있어 손상요인들이 혼 재되어 있을 경우 발생할 수 있는 분석자의 주관에 의한 오류를 개선할 수 있다는 장점을 가진다. 하지만 태양을 광원으로 하는 야외 초분광 영상 촬영 현장상황을 고려할 때, 기상 조건의 변화로 인해 발생하는 광량의 변화 및 측정 시점별로 발생하는 카메라 위치의 오차가 발생한다. 이와 같은 변수는 영상의 품질에 영향을 주며, 반사율의 변화를 유발한다. 이 외에도 기기에서 발생하는 암전류, 상대습도 등이 영상에 영향을 주는 것으로 알려져 있다.

이를 개선하기 위해 취득한 초분광 영상에 대한 방사 보정과 기하보정을 수행하였다. 방사보정을 위해 모든 영 상은 White reference를 함께 촬영하였다. 이때 $99 \%$ 의 반 사율을 가지는 Spectralon ${ }^{\circledR}$ Targets(Labsphere, USA)을 이 용하였으며, Dark reference는 카메라 셔터를 닫고 촬영하 여 획득하였다. 이후 White reference의 반사율 값을 $99 \%$ 로 하는 상댓값으로 변환하였다.

울주 천전리 각석의 모니터링을 위한 초분광 영상은 동일한 대상을 촬영하였으나, 측정 시스템의 한계로 인해
촬영 기준점, 기하조건 등이 상이하다. 특히 운용 중인 초 분광 시스템은 원격탐사 분야에서 사용하는 인공위성이 나 항공 영상과 차이가 있다. 원격탐사 분야에서 활용하 는 위성이나 항공 초분광 영상은 공간정보와 기하조건에 대한 보조자료가 존재하나, 문화재 촬영을 위한 초분광 시스템은 기하조건에 대한 보조자료가 제공되지 않는다.

따라서 이 연구에서는 공간정보 및 기하조건의 한계를 개선하고자 2014년을 기준으로 결합점을 생성하여 기하 보정을 수행하였다. 영상 간 기하보정 및 보간법의 적용 을 위해 L3Harris(USA) 사의 ENVI 5.6을 사용하였고, 식 생지수 산출 및 비교에도 동일한 소프트웨어를 활용하였 다. 보정이 완료된 영상은 분석 정확도를 높이고자 불필 요한 영역을 제거하였다.

\section{4. 연구 결과}

\section{1. 식생지수 선정}

2014년을 기준으로 울주 천전리 각석의 표면에서는 주 로 조류, 지의류로 인한 손상이 관찰되며, 국소부위에서 선태류에 의한 생물오염이 확인된다(Figure $2 \mathrm{~A} \sim \mathrm{C}$ ). 중앙 에는 우수로 인해 발생한 것으로 추정되는 생물오염이 나 타나고(Figure 2D), 각석 상부에는 관목과 초본류의 생장 이 확인된다(Figure $2 \mathrm{E}$ ). 특히 각석 하단과 좌 - 우측에 녹 색 조류, 지의류, 자색 조류 등의 복합적인 오염이 관찰되
A
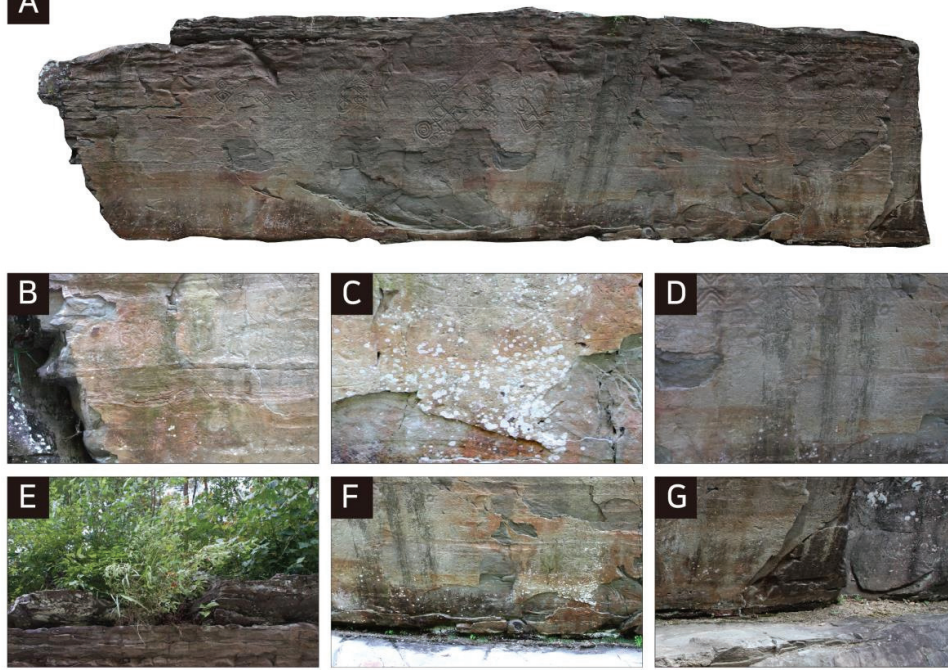

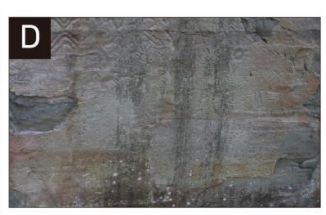

G

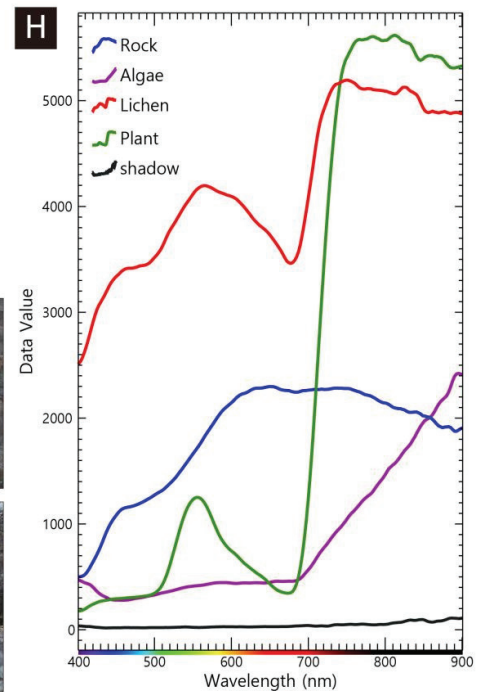

Figure 2. Current status and biological pollution of Petroglyphs of Cheonjeon-ri, Ulju. (A) Status of Petroglyphs in Cheonjeon-ri, Ulju. (B, C) Pollution caused by algae and lichen. (D) Biological pollution in areas where moisture is maintained. (E) Shrubs and herbaceous plants at the top of petroglyphs. (F) Site A. (G) Site B. (H) Spectral characteristics of surface contaminants. 
며, 지면과 가까운 부분에 생물이 집중적으로 분포한다. 이 같은 생물오염은 각각의 특성에 따라 초분광 영상에서 나타나는 분광 곡선의 형태 및 특징이 상이하다(Figure $2 \mathrm{H})$.

분광 특성에 따른 차이를 활용하는 식생지수에 대하여 Zarco-Tejada et al.(2004)는 구조적 지수와 엽록소 지수를 구분하여 제안하였고, Kim et al.(2012)은 앞서 제안된 식 생지수와 추출된 식생의 Endmember의 상관관계를 분석 하여 적합한 식생지수를 산정하는 연구를 수행하였다. 또 한 Chun et al.(2015)은 NDVI를 활용하여 숭례문 육축을 진단한 사례가 있다.

이 연구에서는 선행 연구를 참고하여 식생지수 중 Normalized Difference Vegetation Index (NDVI), Modified Chlorophyll Absorption in Reflectance Index 1 (MCARI 1), Modified Triangular Vegetation Index 1 (MTVI 1), Optimized Soil-Adjusted Vegetation Index (OSAVI), Renormalized Differene Vegetation Index (RDVI), Gitelson \& Merzlyak, Modified Chlorophyll Absorption in Reflectance Index (MCARI), Triangular Vegetation Index (TVI), Zarco- Tejada \& Miller, Gitelson and Merzlyak를 선정하고 비교하였다. 각 식생지수에 대한 산출식은 Table 1과 같다.

식생지수 선정을 위한 단계에서는 야외에서 수습된 암 석을 활용하였다. 실내에서 수행된 사전테스트를 통해 총 9가지 식생지수 공식을 적용하였고, 각각의 결과를 그레 이스케일 이미지로 표현하였다(Figure 3). 이때 식생지수 산출값에 대하여 생물오염부와 비오염부의 비율을 산출 하여 비교하였고, 생물의 종류에 따른 편차가 낮을 때 모 니터링이 용이하였다. 따라서 이와 같은 특성을 고려하여 최종적으로 NDVI, TVI, ZM을 선정하였다. 선정된 식생 지수는 적합성을 평가하기 위해 모니터링 자료 중 2018년
초분광 영상에 적용하여 비교하였다.

이 때 각 식생지수는 서로 상이한 산출값의 범위를 가 지므로 식생지수 비교를 위해 $-1 \sim 1$ 사이의 정규성을 띠 도록 재가공하여 산출값의 범위를 통일하였다. 또한 시각 적으로 용이한 비교를 위해 color index를 삽입하였다.

각각의 생물오염은 상이한 분광특성을 가지고 있으며, 식생지수 산출 시 사용되는 파장에 따라 특정 생물에 대 한 민감도가 달라질 수 있다. 이와 같은 점을 고려하여 산출된 식생지수의 정밀한 비교를 위해 지의류와 조류 영 역에 대한 비교를 수행하였다. 지의류와 조류의 혼합 오 염이 발생한 영역은 site $\mathrm{A}($ Figure $2 \mathrm{~F})$, 조류로 인한 생물오 염이 관찰되는 영역은 site $\mathrm{B}$ 로 설정하였고(Figure $2 \mathrm{G}$ ), 영 역을 지정하여 비교하였다(Figure 4).

산출된 식생지수를 비교한 결과, 일부 영역에서 차이 가 나타나는 것이 확인되었다. NDVI의 경우 site $\mathrm{A}$ 에서 지의류가 저평가되어 암석과 유사한 값으로 분포하는 것 이 확인된다. TVI는 site A에서 상대적으로 지의류 영역이 잘 구분된 것을 알 수 있지만, site B에서 조류로 인한 오 염이 저평가되는 것이 확인된다. $\mathrm{ZM}$ 은 산출된 값이 매우 협소한 분포를 보여 모니터링을 위한 식생지수로 활용이 어려울 것으로 사료된다. 이를 종합하면, 울주 천전리 각 석의 장기 모니터링을 위해 사용할 수 있는 식생지수는 $\mathrm{NDVI}$ 와 TVI로 판단된다.

\section{2. 장기 모니터링 결과 비교}

장기 모니터링에 대한 현장 적용성을 검토하기 위해 실내 실험을 통해 선정된 식생지수를 2014 2020년까지 4회에 걸쳐 구축된 초분광 영상 자료에 적용하여 비교하 였다. 각 식생지수는 사전 검토 단계와 동일한 방법으로

Table 1. Vegetation index formula for monitoring Petroglyphs of Cheonjeon-ri, Ulju

\begin{tabular}{ccc}
\hline Vegetation index & Formula & Reference \\
\hline NDVI & NDVI $=\left(R_{800}-R_{680}\right) /\left(R_{800}+R_{680}\right)$ & $\begin{array}{c}\text { Rouse et al. (1974), } \\
\text { Chun } \text { et al. (2015) }\end{array}$ \\
\hline MCARI $_{1}$ & MCARI $_{1}=1.2^{*}\left(2.5^{*}\left(R_{800}-R_{670}\right)-1.3^{*}\left(R_{800}-R_{550}\right)\right)$ & Haboudane et al. (2004) \\
\hline MTVI & MTVI $=1.2^{*}\left(1.2^{*}\left(R_{800}-R_{500}\right)-2.5^{*}\left(R_{670}-R_{550}\right)\right)$ & Haboudane et al. (2004) \\
\hline OSAVI & OSAVI $=(1+0.16)^{*}\left(R_{800}-R_{670}\right) /\left(R_{800}+R_{670}+0.16\right)$ & Rondeaux et al. (1996) \\
\hline RDVI & $\mathrm{RDVI}=\left(R_{800}-R_{670}\right) / \sqrt{R_{800}-R_{670}}$ & Haboudane et al. (2004) \\
\hline Gitelson \& Merzlyak & $\mathrm{GM}=R_{750} / R_{550}$ & Gitelson and Merzlyak (1996) \\
\hline MCARI & MCARI $=\left[\left(R_{700}-R_{670}\right)-\left(0.2^{*}\left(R_{800}-R_{550}\right)\right) *\left(R_{700} / R_{670}\right)\right.$ & Daughtry et al. (2000) \\
\hline TVI & TVI $=0.5^{*}\left(120^{*}\left(R_{750}-R_{550}\right)-200^{*}\left(R_{670}-R_{550}\right)\right)$ & Broge and Leblanc (2001) \\
\hline Zarco-Tejada \& Miller & $\mathrm{ZM}=R_{750} / R_{710}$ & Zarco-Tejada et al. (2001) \\
\hline
\end{tabular}



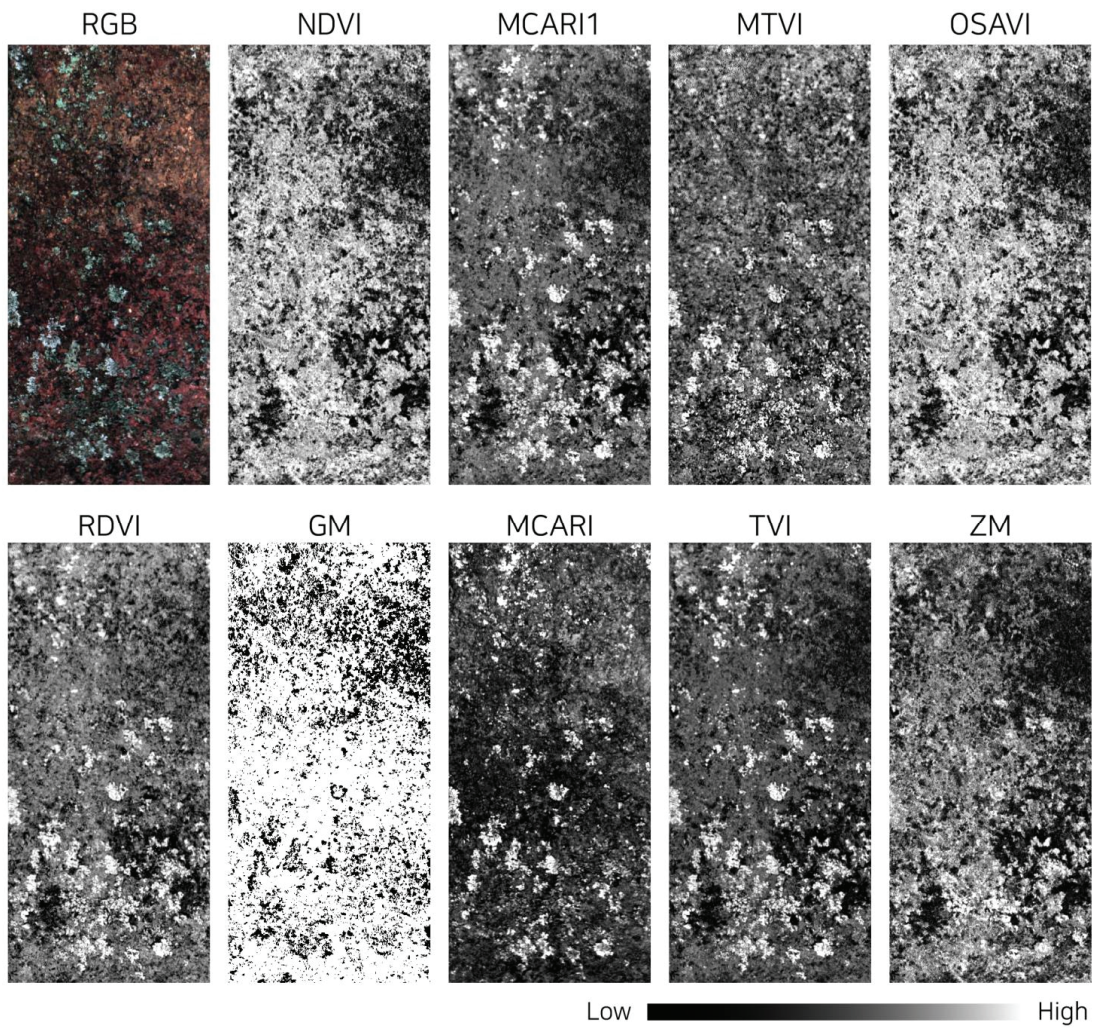

Figure 3. Vegetation index pre-test results.

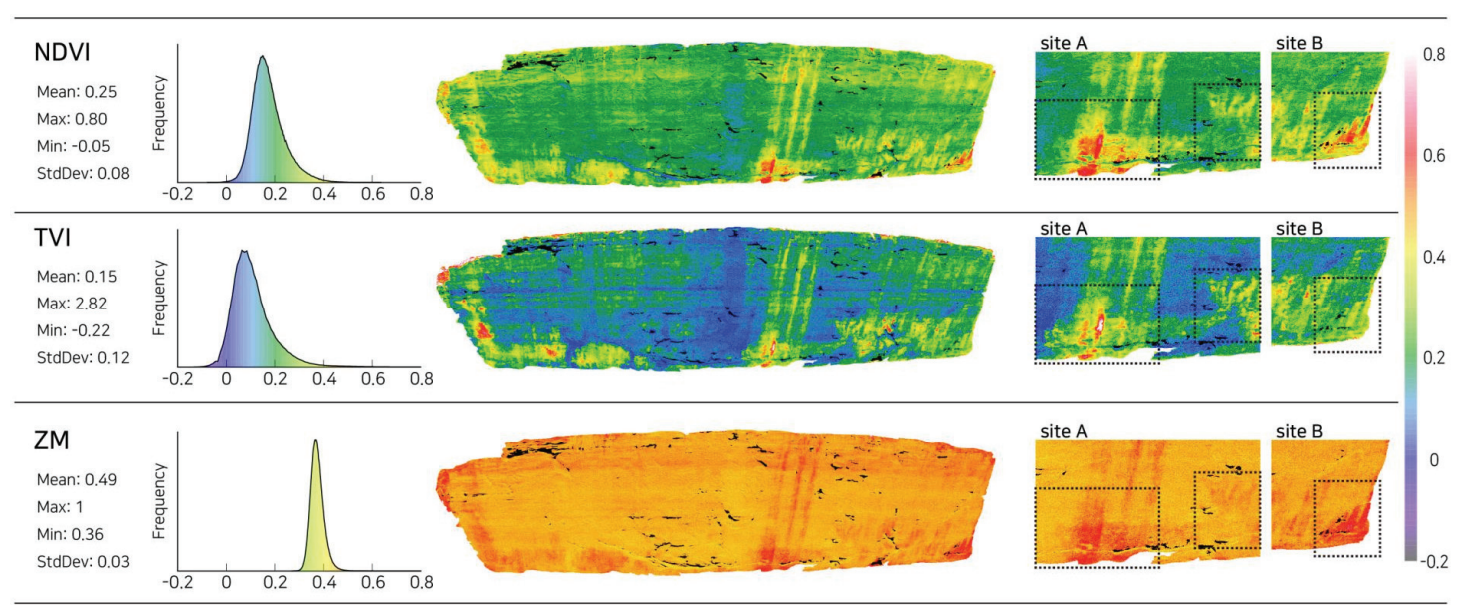

Figure 4. Comparison results of selected vegetation index.

산출결과를 재가공하였다.

\subsection{NDVI}

정규화 식생지수(Normalized Difference Vegetation Index, NDVI)는 녹색식물의 상대적 분포와 활동성, 엽면 적지수, 엽록소의 함량 등과 관련한 지표로 사용되며 단
위가 없다. 적색 $(680 \mathrm{~nm})$ 과 근적외선 영역 $(800 \mathrm{~nm})$ 에서의 반사도를 사용해 계산되고, Rouse et al.(1974)에 의해 처 음 제안되었다. 정규화 식생지수는 -1 에서부터 1 까지의 범위를 가지며, 증가하는 양수(+) 값은 녹색식물의 증가 를 의미한다. 반대로 음수(-) 값은 물, 황무지, 얼음, 혹은 구름과 같이 식생이 존재하지 않는 지역을 나타낸다(Sung 
et al., 2003).

NDVI에 대한 모니터링 수행 결과, 평균값은 2014년 $0.19,2016$ 년 $0.25,2018$ 년 $0.25,2020$ 년 0.21로 나타난다. 2014년부터 2016년까지는 식생지수가 증가하며, 2018년 에 정체되고, 2020년은 보존처리로 인해 NDVI 값이 낮아 지는 것을 알 수 있다(Table 2). 정밀한 비교를 위해 site $\mathrm{A}$ 와 site $\mathrm{B}$ 를 함께 비교한 결과, site $\mathrm{A}$ 의 지수는 0.22 에서 0.28 로 증가하는 것이 확인되었으며, 2020년 보존처리 이 후 0.22 로 다시 감소하는 것이 확인된다. Site B도 마찬가 지로 0.27 에서 0.34 로 증가 경향을 보였으며, 보존처리 이 후 0.23 으로 확연하게 생물 활력도가 낮아진 것이 확인되 었다(Figure 5).

그러나 이러한 식생지수의 평균값은 시각적인 변화를 충분히 반영하지 못하는 경향이 나타난다. 이 때 생물의 밀집도가 높은 영역인 site $\mathrm{A}$ 와 site $\mathrm{B}$ 에서는 모니터링 결 과 비교가 용이한 것으로 판단된다. 또한 보존처리 이후
식생지수가 낮아지는 경향이 확인되어, 보존처리 전·후 비교에 식생지수의 활용이 가능한 것을 알 수 있다.

\subsubsection{TVI}

TVI는 엽록소에 의한 빛 흡수가 상대적으로 낮은 녹색 영역의 반사도 및 적색과 근적외선 반사도 간의 상대적 차이에 대한 함수로서 색소에 의해 흡수된 복사에너지를 의미한다. 이 지수는 스펙트럼 공간에서 녹색의 최대점, 엽록소 흡수에 의한 최소점, 근적외선 영역으로 정의된 삼각형의 면적으로 계산되며, 이는 적색 반사율을 감소시 키는 엽록소 흡수와 근적외선 반사도 증가를 유발하는 다 량의 잎 조직이 삼각형의 전체 면적을 증가시킨다는 사실 에 근거한다(Broge and Leblanc, 2001).

TVI에 대한 모니터링 수행 결과, 평균값은 2014년 0.16, 2016년 0.20, 2018년 0.17, 2020년 0.49로 나타난다. 전체 산출값을 활용한 평균의 비교 결과, 경향성이 보이

Table 2. NDVI value results for 2014-2020

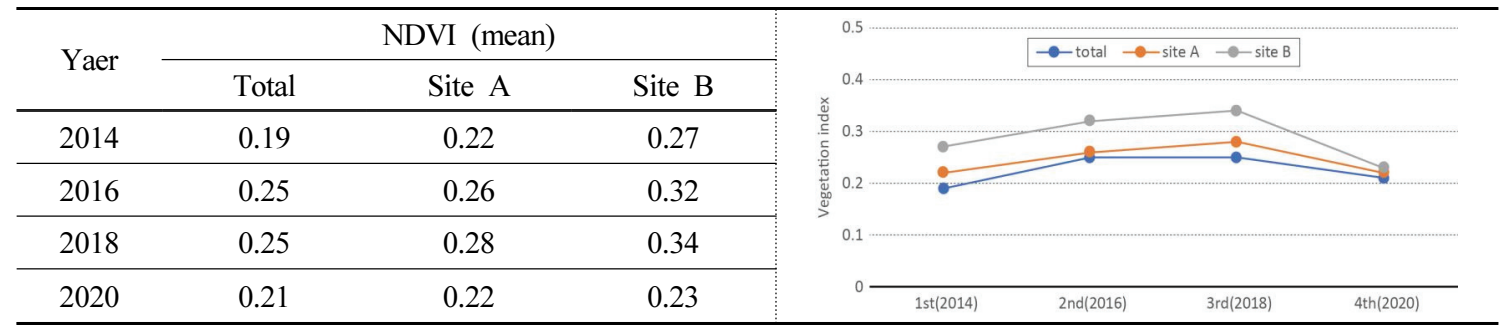

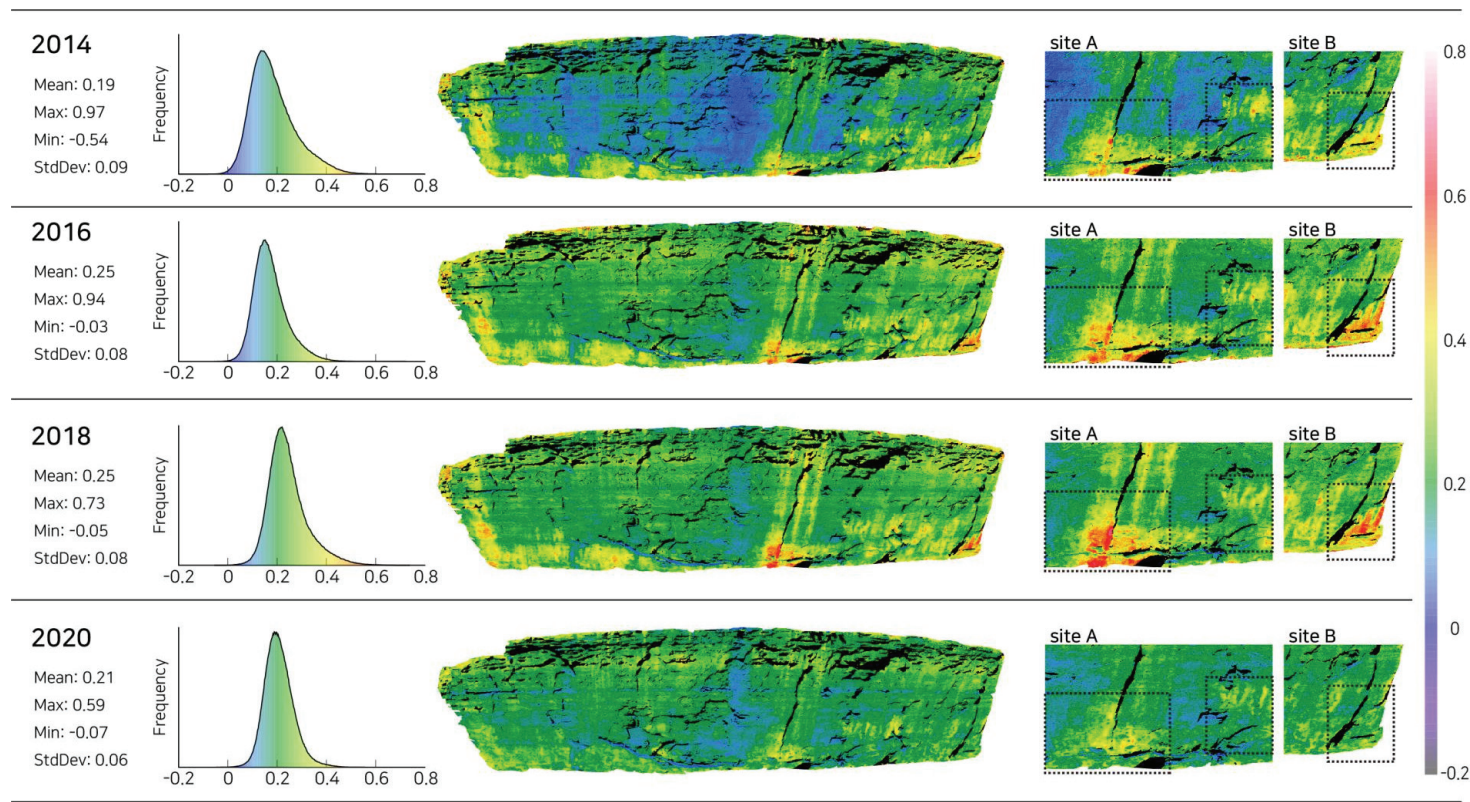

Figure 5. Long-term monitoring results of NDVI images. 
지 않는 것이 확인된다(Table 3). 특히 보존처리 이후인 2020년 모니터링 결과, 2018년에 비해 식생지수가 0.17에 서 0.49 로 증가하는 경향이 나타났다. 정밀한 관찰을 위해 수행된 site $\mathrm{A}$ 와 site $\mathrm{B}$ 의 관찰 결과에서 site $\mathrm{B}$ 는 식생지수 가 지속적으로 감소하는 경향이 나타났지만 site $\mathrm{A}$ 는 2020 년 보존처리 후 오히려 증가하는 것이 확인되었다(Figure 6). 이는 울주 천전리 각석의 보존처리 결과와 상반되므로 $\mathrm{TVI}$ 는 모니터링에 활용하기 어려울 것으로 사료된다.

이와 같은 결과는 TVI를 산출하는 공식에서 기인하는 것으로 판단된다. 특히 기하조건과 측정조건이 상이한 영 상의 특성을 고려했을 때, 측정시기마다 영상의 분광반사 도가 상이하게 나타날 수 있다. 분광반사도는 방사보정을 통해 다소 보정이 가능하지만, 완벽하게 보정되지 않는다. 따라서 분광반사도의 변화는 TVI 산출값의 차이를 유발하 게 되며, 이전 모니터링 시점보다 분광반사도가 낮을 경우 생물오염도가 감소하는 경향으로 나타날 가능성이 높다.

\section{5. 고찰 및 결론}

이 연구에서는 울주 천전리 각석의 표면에 서식하는 생물의 모니터링을 위해 식생지수를 적용하는 연구를 수 행하였다. 먼저 모니터링 현장에 적합한 식생지수 선정을 위해 사전테스트를 수행한 결과, NDVI, TVI, ZM이 선정 되었다. 선정된 식생지수를 울주 천전리 각석의 2018년 영상에 적용한 결과, $\mathrm{ZM}$ 은 모니터링에 부적합하였으며, $\mathrm{NDVI}$ 와 TVI의 활용이 가능한 것으로 판단되었다. 또한 $\mathrm{NDVI}$ 와 TVI는 각각 조류와 지의류에 대한 민감도에서 차이를 보였으며, 이와 같은 특성을 활용하여 연도별 초 분광 영상의 비교를 수행하였다.

NDVI 분석 결과, 식생지수는 2014 2018년까지 증가 하는 경향이 나타났으며 2020년 보존처리 후 낮아지는 것 이 확인되었다. 그러나 일부 지의류 영역의 경우 NDVI 값이 저평가되는 것을 확인하였으며, 각 연도별 비교 결

Table 3. TVI value results for $2014-2020$

\begin{tabular}{|c|c|c|c|c|c|c|}
\hline \multirow{2}{*}{ Year } & \multicolumn{3}{|c|}{ TVI (mean) } & \multicolumn{2}{|c|}{$0.5-\rightarrow$-total $\rightarrow-$ - site A $\rightarrow-$ - site B } & \\
\hline & Total & Site A & Site B & \multirow{3}{*}{0.4} & & \\
\hline 2014 & 0.16 & 0.21 & 0.28 & & & \\
\hline 2016 & 0.20 & 0.23 & 0.27 & & $\Rightarrow$ & 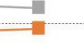 \\
\hline 2018 & 0.17 & 0.18 & 0.24 & $0.1 \ldots$ & & \\
\hline 2020 & 0.49 & 0.19 & 0.23 & $0 \longdiv { 1 s t ( 2 0 1 4 ) }$ & 2 nd(2016) & $4 \operatorname{th}(2020)$ \\
\hline
\end{tabular}

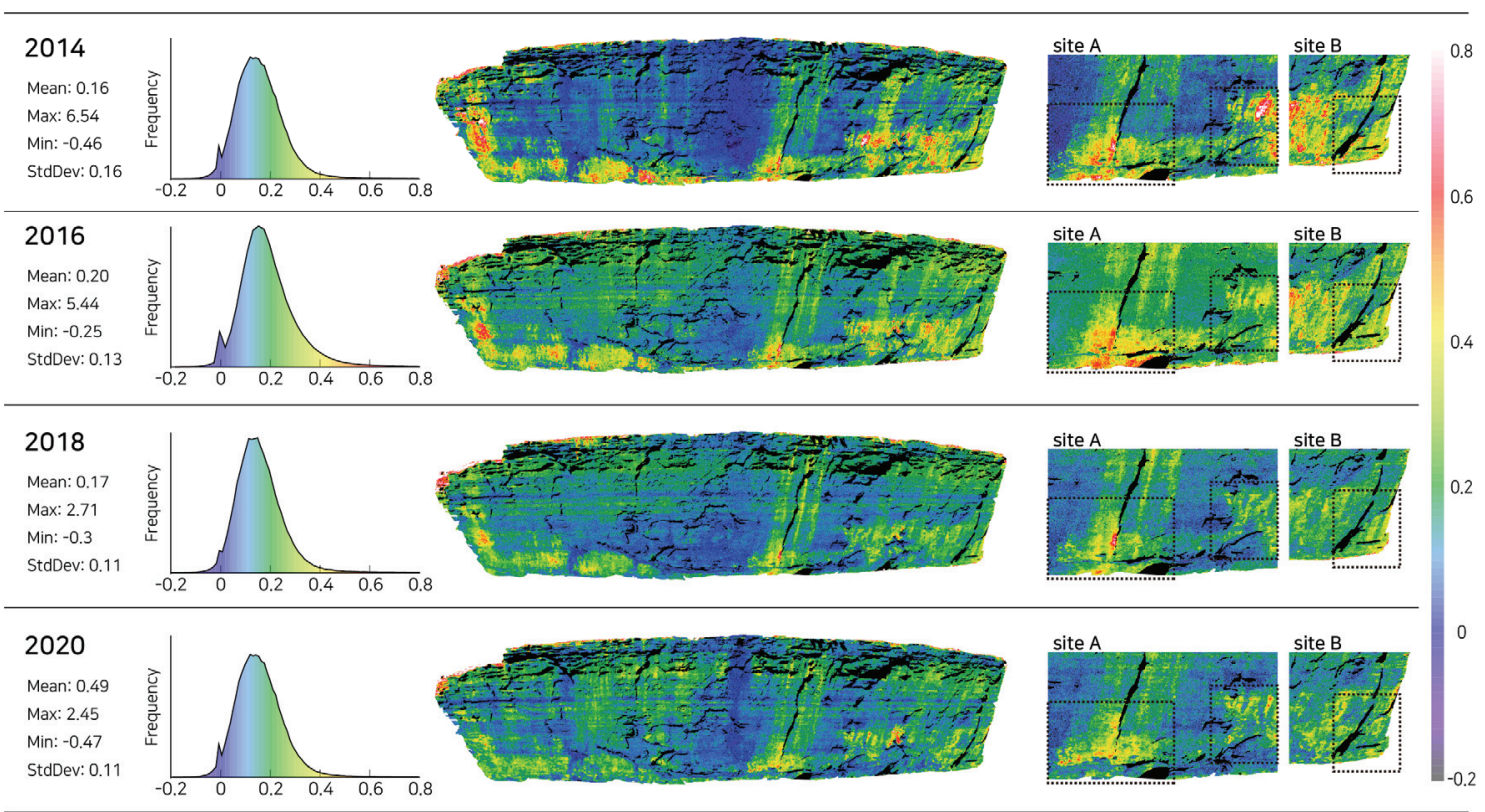

Figure 6. Long-term monitoring results of TVI images. 
과에서도 같은 양상이 나타나는 문제점을 발견하였다. 하 지만 정밀한 관찰을 위해 지정한 site $\mathrm{A}$ 와 site $\mathrm{B}$ 에 대한 분석 결과 전체영역을 비교한 것보다 식생지수의 증가와 감소 경향이 명확하게 나타나는 것을 알 수 있었다.

TVI 분석 결과, 보존처리 이후인 2020년이 오히려 2014년보다 식생지수가 증가하고 있어 NDVI의 결과와 반대되는 경향이 나타났다. site $\mathrm{A}$ 와 site $\mathrm{B}$ 의 비교 결과에 서는 식생지수가 2014년부터 점진적으로 낮아지는 것 이 확인되어 모니터링 시점에 따른 경향성을 찾을 수 없었다.

이와 같은 경향성의 차이는 분광반사율의 차이에서 기 인하는 것으로 판단된다. 특히 식생지수 산출을 위해 사 용된 울주 천전리 각석의 초분광 영상은 연도별 촬영조건 이 모두 상이하며, 촬영조건의 차이는 필연적으로 분광반 사율의 변화를 야기한다. 각 영상의 분광반사율 차이를 줄이기 위해 방사보정과 기하보정을 수행하였음에도 불 구하고, 분광반사도의 변화로 인해 연도별 영상 간 편차 가 발생한다.

이때 각 식생지수는 산출되는 공식의 특성에서 분광반 사도에 대한 민감도가 달라진다. 즉, NDVI는 산출과정에 서 사용되는 파장의 합을 분모로 사용하여 지수 형태로 가공되지만 TVI는 사용되는 파장의 분광반사율의 증감 에 따라 산출값이 변화하게 된다. 그 결과, NDVI는 비교 적 분광반사율의 변화에 따른 영향을 적게 받을 수 있으 나, TVI는 민감하게 영향을 받는 것으로 판단된다.

따라서 NDVI는 측정조건이나 기하조건을 맞추기 어 려운 환경에서 취득된 초분광 영상으로 식생의 활력이나 분포 모니터링을 수행할 수 있을 것으로 판단된다. 반면 TVI는 지의류에 대한 민감도가 NDVI보다 높기 때문에 활용이 가능할 것으로 기대되었으나 모니터링이나 진단 에 사용하기 위해서는 추가적인 연구가 필요하다.

또한 이 연구에서는 장기적인 모니터링에 식생지수를 활용하기 위해서 오염이 집중된 영역을 특정하여 비교하 는 방법을 제안할 수 있을 것으로 사료된다. NDVI를 활용 한 모니터링 결과에서 site $\mathrm{A}$ 와 site $\mathrm{B}$ 의 비교 결과, 전체 면적의 산출값에 비해 상대적으로 식생지수의 증감이 명 확하게 나타났다. 이러한 결과는 모니터링을 위해 영상 전체를 활용하는 것보다, 오염이 발생한 영역을 특정하여 모니터링을 수행하는 것이 효율적임을 방증한다.

위의 내용을 종합하면, 울주 천전리 각석과 같은 야외 석조문화재에 대한 중장기적 모니터링에 식생지수의 활 용이 가능하였다. 다만 식생지수를 활용하여 장기적으로 모니터링을 수행하기 위해서는 심화연구를 통해 광원으 로 사용되는 태양이나 초분광 센서에서 발생하는 기하조
건의 차이와 분광반사율 편차를 줄이는 연구가 필요하며, 이를 통해 보다 정밀한 모니터링이 가능할 것으로 기대 된다.

\section{사 사}

이 연구는 문화재청 국립문화재연구소 "문화유산 융 복합연구(R\&D)"의 지원을 받아 수행된 연구임을 명기하 며, 기관의 지원에 감사드립니다.

\section{REFERENCES}

Ahn, Y.B., Yoo, J.H., Choie, M. and Lee, M.S., 2020, Accuracy assessment and classification of surface contaminants of stone cultural heritages using hyperspectral image-focusing on stone buddhas in four directions at Gulbulsa Temple Site, Gyeongju. Journal of Conservation Science, 36(2), 73-81. (in Korean with English abstract)

Broge, N.H. and Leblanc, E., 2001, Comparing prediction power and stability of broadband and hyperspectral vegetation indices for estimation of green leaf area index and canopy chlorophyll density. Remote Sensing of Environment, 76(2), 156-172.

Cecchi, G., Pantani, L., Raimondi, V., Tomaselli, L., Lamenti, G., Tiano, P. and Chiari, R., 2000, Fluorescence lidar technique for the remote sensing of stone monuments. Journal of Cultural Heritage, 1(1), 29-36.

Chun, Y.G., Lee, J.M., Lee, M.H., Park, S.M., Lee, S.M. and Lee, M.S., 2014, Long term monitoring of deterioration condition for the rock-carved Buddha Triad in Seosan, Korea. Journal of Conservation Science, 30(4), 439-446. (in Korean with English abstract)

Chun, Y.G., Lee, M.S., Kim, Y.R., Lee, M.H., Choi, M.J. and Choi, K.H., 2015, Utilization of hyperspectral image analysis for monitoring of stone cultural heritages. Journal of Conservation Science, 31(4), 395-402. (in Korean with English abstract)

Cultural Heritage Administration, 2016, Report on the monitoring results of cultural heritage subject to intensive management. (in Korea)

Daughtry, C.S., Walthall, C.L., Kim, M.S., de Colstoun, E.B. and McMurtreylii, J.E., 2000, Estimating corn leaf chlorophyll concentration from leaf and canopy reflectance. Remote Sensing of Environment, 74(2), 229-239.

Gitelson, A.A. and Merzlyak, M.N., 1996, Signature analysis of leaf reflectance spectra: algorithm development for remote sensing of chlorophyll. Journal 
of Plant Physiology, 148(3-4), 494-500.

Griffin, P.S., Indictor, N. and Koestler, R.J., 1991, The biodeterioration of stone: a review of deterioration mechanisms, conservation case histories, and treatment. International Biodeterioration, 28(1-4), 187-189.

Haboudane, D., Miller, J.R., Pattey, E., Zarco-Tejada, P.J. and Strachan, I.B., 2004, Hyper- spectral vegetation indices and novel algorithms for predicting green LAI of crop canopies: Modeling and validation in the context of precision agriculture. Remote Sensing of Environment, 90(3), 337-352.

Han, S.H. and An, H.G., 1990, Biological damage factors and conservation measures of stone cultural heritage. Munhwajae Korean Journal of Cultural Heritage Studies, 23, 181-184. (in Korean with English abstract)

Hyun, C.U. and Park, H.D., 2010, Weathering degree assessment of tuff stone monument using reflectance spectroscopy. Journal of the Korean Society of Mineral and Energy Resources Engineers, 48(4), 515-529. (in Korean with English abstract)

Jo, Y.H. and Lee, C.H., 2011, Making method of deterioration map and evaluation techniques of surface and three-dimensional deterioration rate for stone cultural heritage. Journal of Conservation Science, 27(3), 251-260. (in Korean with English abstract)

Jordan, C.F., 1969, Derivation of leaf-area index from quality of light on the forest floor. Ecology, 50(4), 663-666.

Kim, S.H., Ma, J.R., Kook, M.J. and Lee, K.S., 2005, Current status of hyperspectral remote sensing: principle, data processing techniques, and applications. Korean Journal of Remote Sensing, 21(4), 342-343. (in Korean with English abstract)

Kim, T.W., We, G.J. and Suh, Y.C., 2012, Correlation analysis with vegetation indices and vegetationendmembers from airborne hyperspectral data in forest area. Journal of the Korean Association of Geographic Information Studies, 15(3), 52-65. (in Korean with English abstract)

Kim, Y.H., Lee, J.M., Choie, M., Hong, J.Y., Jo, C.W., Kim, S.J. and Jeong, S.Y., 2017, Identification and FT-IR spectrum analysis of lichens on flagpole support in beopjusa temple. Journal of Conservation Science, 33(5), 391-398. (in Korean with English abstract)

Kim, Y.J., Kim, O.J. and Lee, O.M., 2010, The distribution of aerial algae and the assessment of biological pollution class at 8 stone cultural heritages in Korea. Journal of Conservation Science, 26(3), 259-268. (in Korean with English abstract)

Kim, Y.J., Kim, O.J. and Lee, O.M., 2011, The community of aerial algae and the biological pollution coverage at
9 stone cultural heritages in Korea. Journal of Conservation Science, 27(2), 145-154. (in Korean with English abstract)

Kim, Y.R., Lee, M.S., Chun, Y.G., Lee, M.H. and Jwa, Y.J., 2016, Nondestructive deterioration diagnosis and environmental investigation of the stupa of the buddhist monk Soyo in Baegyangsa temple, Jangseong. Munhwajae Korean Journal of Cultural Heritage Studies, 49(4), 52-63. (in Korean with English abstract)

Lee, C.B., Koh, S.C., Moon, B.Y., Park, I.H., Park, P.B. and Chun, H.S., 2016, Plant physiology $2^{\text {nd }}$ Ed. Life Science Publishing Co., Seoul, 72-74. (in Korean with English abstract)

Lee, C.H., Choi, S.W., Han, K.S. and Won, K.S., 2001, Approach to conservation sciences and mechanical deteriorations of the Seoagdong Standing Triple Buddha, Gyeongju, Korea. Journal of the Geological Society of Korea, 37, 612-622. (in Korean with English abstract)

Lee, M.S., Choie, M., Lee, T.J. and Chun, Y.G., 2020, Deterioration characteristic analysis for stone properties in the Taereung royal tomb of the Joseon dynasty using nondestructive analysis. Munhwajae Korean Journal of Cultural Heritage Studies, 53(2), 222-241. (in Korean with English abstract)

Lee, M.S., Choie, M., Yoo, J.H. and Ahn, Y.B., 2019, Material analysis and surface condition monitoring of standing Buddha statue in the Gwanchoksa temple, Nonsan, Korea. The Journal of the Petrological Society of Korea, 28(4), 227-236. (in Korean with English abstract)

Lee, M.S., Kim, K.S., Min, G.H., Son, D.H., Kim, J.E. and Kim, S.C., 2019, Recent trends of hyperspectral imaging technology. Electronics and Telecommunications Trends, 34(1), 87-88. (in Korean with English abstract)

Min, G.H., 1985, The effects of lower plants on stone cultural heritage. Conservation Studies, 6, 4-8. (in Korean with English abstract)

Min, G.H., 2018, Cultural heritage and biology: biodeterioration. Bioscience, Gyeonggido, 35-49. (in Korea)

Na, S.I., Park, C.W., So, K.H., Ahn, H.Y. and Lee, K.D., 2018, Application method of unmanned aerial vehicle for crop monitoring in Korea. Korean Journal of Remote Sensing, 34(5), 832-833. (in Korean with English abstract)

National Research Institute of Cultural Heritage, 2009, Survey report on the actual measurement and evaluation of damage of petroglyphs of Cheonjeon-ri, Ulju. (in Korea)

Oh, I.H., 2008, Isolation and identification of cyanobacteria of the cultural heritages in the Gwanschoksa, Nonsan city in Korea. The Journal of Natural Sciences, 19(1), 
27-35. (in Korean with English abstract)

Pantani, L., Ballerini, G., Cecchi, G., Edner, H., Lognoli, D., Johansson, T. and Weibring, P., 2000, Experiments on stony monument monitoring by laser-induced fluorescence. Journal of Cultural Heritage, 1, S345-S348.

Park, J.S., Woo, J.J., Oh, S.H. and Oh, S.O., 2020, A study on lichen diversity in the placenta chamber of prince king Sejong's sons, Seongju. Journal of Conservation Science, 36(2), 93-102. (in Korean with English abstract)

Park, S.M., Chun, Y.G. and Lee, M.S., 2013, Monitoring technology on the surface condition after conservation treatment of stone cultural heritage. Conservation Studies, 34, 32-48. (in Korean with English abstract)

Penuelas, J. and Filella, I., 1998, Visible and near-infrared reflectance techniques for diagnosing plant physiological status. Trends in Plant Science, 3(4), 151-152.

Rondeaux, G., Steven, M. and Baret, F., 1996, Optimization of soil-adjusted vegetation indices. Remote Sensing of Environment, 55(2), 95-107.

Rouse, J.W., Haas, R.H., Schell, J.A., Deering, D.W. and Harlan, J.C., 1974, Monitoring the vernal advancement and retrogradation (green wave effect) of natural vegetation. NASA/GSFC Type III Final Report, Greenbelt, Md, 371.
Shin, S.C. and Kim, C.J., 2003, Application of normalized difference vegetation index for drought detection in Korea. Journal of Korea Water Resources Association, 36(5), 841-842. (in Korean with English abstract)

Sung, C.J. and Jung, J.C., 2003, A study on change of NDVI according to the terrain element. Journal of the Korean Association of Geographic Information Studies, 6(2), 94-95. (in Korean with English abstract)

Vázquez, M.A., Galán, E., Guerrero, M.A. and Ortiz, P., 2011, Digital image processing of weathered stone caused by efflorescences: A tool for mapping and evaluation of stone decay. Construction and Building Materials, 25(4), 1603-1611.

Zarco-Tejada, P.J., Miller, J.R., Noland, T.L., Mohammed, G.H. and Sampson, P.H., 2001, Scaling-up and model inversion methods with narrowband optical indices for chlorophyll content estimation in closed forest canopies with hyperspectral data. IEEE Transactions on Geoscience and Remote Sensing, 39(7), 1491-1507.

Zarco-Tejada, P.J., Berjón, A. and Miller, J.R., 2004, Stress detection in crops with hyperspectral remote sensing and physical simulation models. Airborne Imaging Spectroscopy Workshop, Bruges, Belgium, 8 October. 